\begin{tabular}{|c|c|}
\hline$S$ sciendo & 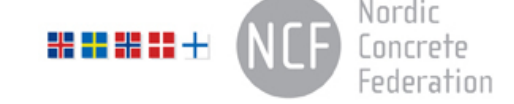 \\
\hline $\begin{array}{l}\text { Article authors. This is an open access article } \\
\text { distributed under the Creative Commons Attribution- } \\
\text { NonCommercial-NoDerivs } \\
\text { (http://creaticecommons.org/licenses/by.nc-nd/3.0/). }\end{array}$ & $\begin{array}{l}\text { ISSN online } 2545-2819 \\
\text { ISSN print } \quad 0800-6377\end{array}$ \\
\hline DOI: $10.2478 /$ ncr-2020-0015 & $\begin{array}{r}\text { Received: Sept. 28, } 2020 \\
\text { Rev. received: Nov. 26, } 2020 \\
\text { Accepted: Nov. 26, } 2020\end{array}$ \\
\hline
\end{tabular}

\title{
Alkali-reduced Bauxite Residue as Novel SCM
}

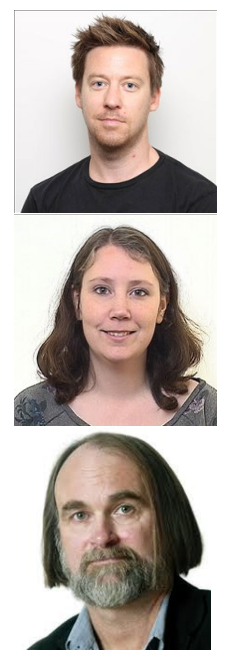

Tobias Danner, $\mathrm{PhD}$

Scientist, SINTEF Community

Høgskoleringen 7B, 7034 Trondheim

Tobias.danner@sintef.no

Malin Sletnes

Scientist, SINTEF Community

Høgskoleringen 7B, 7034 Trondheim

Malin.sletnes@sintef.no

Harald Justnes, PhD

Chief scientist, SINTEF Community

Høgskoleringen 7B, 7034 Trondheim

Harald.justnes@sintef.no

\section{ABSTRACT}

Bauxite residue is a major waste stream available in large volumes globally that can cause risks to the surrounding environment (e.g. ecotoxicity) when disposed and stored by conventional methods. There is yet no large-scale application and the utilization as supplementary cementitious material might be the best way to re-use bauxite residue. The main obstacle for the utilization of bauxite residue in the construction industry is the high alkalinity. This paper presents first results of a study on alkali reduction of bauxite residue by acetic acid treatment and the potential application of this alkali reduced bauxite residue as pozzolan in cementitious binders. A process of alkali reduction is presented that can help solving waste management problems of alumina refineries by transforming bauxite residue to a less hazardous waste, while producing a reactive pozzolan and Na-acetate that can find application in the construction and infrastructure market. $90 \%$ alkalinity reduction of bauxite residue could be achieved by simply washing with diluted acetic acid. Alkali-reduced bauxite residue showed good pozzolanic reactivity regarding portlandite consumption, bound water and 28-day compressive strength of mortars with $20 \%$ replacement of OPC.

Key words: Bauxite residue, red mud, pozzolan, cement, acetic acid, alkali reduction, sodium acetate 
Bauxite residue (BR; also called "red mud" due to its characteristic red colour) is a waste product from the Bayer process in making alumina as raw material for aluminium metal production. During the Bayer process, bauxite is digested with caustic soda $(\mathrm{NaOH})$, dissolving the present aluminium hydroxides to form a soluble solution of sodium aluminate. BR comprises the insoluble impurities and can be separated from the soluble aluminates in a clarification step. The soluble aluminates are subsequently precipitated and transferred to solid alumina $\left(\mathrm{Al}_{2} \mathrm{O}_{3}\right)$ serving as raw material for aluminium metal electrolysis. BR exits the Bayer process as a highly alkaline slurry of $\mathrm{pH} 10-13.5$ with a solid content between 15 and $40 \%$ [1] and is pumped away for disposal and often stored in open ponds [2]. Due to its high alkaline nature, $\mathrm{BR}$ is regarded a hazardous waste. In 2019, over 130 million tonnes of alumina $\left(\mathrm{Al}_{2} \mathrm{O}_{3}\right)$ were produced from bauxite [3], mainly utilizing the Bayer process. On a global average between 1 and 1.5 tonnes of BR are produced per ton of alumina [2], which means that about 175 million tonnes of BR were produced in 2019. With about 80 active Bayer plants and more than 50 closed sites [2] the total amounts of stockpiled and available BR were estimated to be around 3000 million tonnes by the end of 2010 [4]. In 2018, the global inventory reached 4600 million tonnes [5]. Bauxite residue has a complex chemical composition and consists of several crystalline phases, mainly iron and aluminium oxides and hydroxides but also including desilication products like sodalite and cancrinite, besides e.g. quartz, rutile and many minerals in addition to some organic materials [6-8]. Despite ongoing research there is yet no large-scale application for the utilization of BR.

In 2017, 4.1 billion tonnes of cement were produced worldwide [9] rendering it the largest manufactured product on earth. Data from 2016 showed that on a global average, $842 \mathrm{~kg} \mathrm{CO} 2$ are produced per ton of cement clinker [10]. Due to the vast amounts of cement produced, it is estimated that cement production contributes between 5 and $8 \%$ of total anthropogenic $\mathrm{CO}_{2}$ emissions. Based on a recent report initiated by the United Nations Environmental Programme, the increased use of SCMs (supplementary cementitious materials) as partial replacement for Portland cement clinker is recommended as a main path to substantially decrease global $\mathrm{CO}_{2}$ emissions associated with the cement and concrete industry [11].

On industrial scale, the most commonly used SCM implemented in blended cements today (including Norway) is fly ash, a waste product from coal firing power plants. However, the availability of high-quality fly ash will decrease within a relatively short time and European cement producers have started to look for large volume alternatives to partly or completely replace fly ash in the future. Due to the large amounts of BR available worldwide, it would be beneficial to consider the utilization of BR as a SCM.

Recent efforts in utilizing BR as a cement replacement material has been summarized [7, 12, 13]. Almost all studies performed and described in the mentioned references, used BR "as is" without further treatment and investigated the effect of BR on mechanical properties. The chemistry and mineralogy of global BR deposits varies significantly. Depending on the process conditions, BR can contain up to $10 \% \mathrm{Na}_{2} \mathrm{O}$ [2]. High alkalinity can be an advantage when $\mathrm{BR}$ is used as activator for other alumino-silicate materials, e.g. fly ash in blended cements [14] or geopolymers [7]. However, for the application in common cementitious materials the high alkalinity is the major obstacle for implementation of BR. Untreated BR can show good 
pozzolanic reactivity in cementitious systems [15], however, the risk of causing deleterious alkali-aggregate reactions (AAR) in concrete does not allow its current use. AAR is a major durability concern in many countries including Norway. High alkalinity may also negatively affect the long-term strength development $[14,15]$. Furthermore, the amount of BR that can be used as part of the raw meal for cement clinker production is also limited by amongst others the high alkalinity [16]. To make cementitious binders more sustainable, a minimum clinker replacement of $20 \%$ should be targeted, which requires a significant alkali reduction of BR.

Decreasing the $\mathrm{Na}_{2} \mathrm{O}$ content of $\mathrm{BR}$ is not only important for the utilisation in cementitious materials but is also a consideration for waste management at alumina producing plants. Decreasing the alkalinity $(\mathrm{pH})$ can avoid the classification of BR as hazardous material, which would decrease potential transport costs and facilitate the re-use in other industries or even revegetation of disposal sites. Several approaches are being tested to neutralize BR in the laboratory, e.g. treatment with Fe- or Al-sulphates [17]. Other efforts to reduce the $\mathrm{pH}$ and the soluble $\mathrm{Na}$ content of BR include mineral acid or seawater neutralization, $\mathrm{CO}_{2}$ treatment, bioleaching and sintering [18]. A recent review article focuses especially on alkalinity reduction of BR by utilization of industrial wastes such as waste acid, brines or biomass and effects on vegetation establishment at disposal sites [5]. Waste control by using other wastes might be an economical feasible and sustainable strategy with respect to reducing waste disposal. However, there are still problems with potential secondary pollution or risk of salination and undesirable effects on plant growth that limit the implementation [5].

As most of these studies focus on waste management without further application in the cement sector, the neutralized BR product has often experienced considerable changes in mineralogy and chemistry which can result in low reactive materials and might bring along other durability issues for the final product. Cooking of BR with calcium hydroxide can reduce the alkalinity of BR by $75 \%$ while rendering a product with chemical reactivity higher than fly ash [15]. However, the described process would be difficult to implement on industrial scale and also involve $\mathrm{CO}_{2}$-emissions by producing calcium hydroxide. Neutralization of BR by mixing with lime for the use as construction material has been investigated [19]. Based on a recent publication, looking at soil formation from BR deposits for sustainable plant colonialization [20] we intend to carry out in this study a simple washing process of BR with diluted acetic acid to produce a low alkali SCM. The proposed approach has the potential to be implemented on industrial scale and could help solving waste management problems of alumina plants while at the same time producing a novel large volume SCM and thus decreasing the $\mathrm{CO}_{2}$ footprint of common cementitious binders.

\section{MATERIALS}

Bauxite residue (BR) was obtained from an alumina refinery in Brazil. The dried BR was milled down with an automortar model RETSCH RM 200 for $5 \mathrm{~min}$ at highest pestle pressure. For further characterisation of the material and use in cement pastes and mortars, the dried and milled down BR was used.

For cement paste and mortar experiments, a low-alkali sulphate resistant $\left(\mathrm{C}_{3} \mathrm{~A}\right.$ content $\left.<3 \%\right)$ cement with low early heat development was used (CEM I 42.5 N-SR $3 \mathrm{MH} / \mathrm{LA}$ ). Limestone 
filler (LL) was used as received from Norcem AS for mortar and paste experiments. The chemical composition of all materials is given in Table 1. The mineralogical composition of $\mathrm{BR}$ is given in Table 2. The particle size distributions of cement, limestone filler and BR are given in Figure 1.

Table 1 - Chemical composition of CEM I, LL and BR in weight \%, determined with X-ray fluorescence (XRF)

\begin{tabular}{lccc}
\hline Oxides & CEM I $^{1}$ & $\begin{array}{c}\text { LL } \\
\text { (Weight \%) }\end{array}$ & BR \\
\hline $\mathrm{CaO}$ & 62.2 & 43.8 & 1.7 \\
$\mathrm{SiO}_{2}$ & 21.0 & 13.2 & 16.0 \\
$\mathrm{Al}_{2} \mathrm{O}_{3}$ & 0.2 & 3.4 & 18.9 \\
$\mathrm{Fe}_{2} \mathrm{O}_{3}$ & 4.9 & 1.7 & 37.9 \\
$\mathrm{TiO}_{2}$ & - & 0.2 & 6.2 \\
$\mathrm{MgO}$ & 1.9 & 1.7 & $<0.1$ \\
$\mathrm{~K}_{2} \mathrm{O}$ & 0.4 & 0.7 & 0.1 \\
$\mathrm{Na}_{2} \mathrm{O}$ & 0.3 & 0.2 & 9.6 \\
$\mathrm{SO}_{3}$ & 2.6 & 0.6 & - \\
$\mathrm{Mn}_{2} \mathrm{O}_{3}$ & 0.5 & - & - \\
$\mathrm{P}_{2} \mathrm{O}_{5}$ & 0.2 & - & - \\
$\mathrm{LOI}^{2}$ & 2.1 & 33.4 & 7.8 \\
\hline $\mathrm{SUM}^{2}$ & 96.2 & 99.0 & 98.3 \\
\hline
\end{tabular}

${ }^{1}$ Average result 2019-2020 provided by Norcem AS, Brevik, Norway

${ }^{2}$ LOI: Loss on ignition

Table 2 - Mineralogical composition of bauxite residue determined by X-ray diffraction (XRD) and Rietveld analysis

\begin{tabular}{lll}
\hline Mineral name & $\mathrm{Chemical}_{\text {formula }}$ & Rietveld weight \% \\
\hline Quartz & $\mathrm{SiO}_{2}$ & 2.1 \\
Ilmenite & $\mathrm{FeTiO}_{3}$ & 1.5 \\
Hematite & $\mathrm{Fe}_{2} \mathrm{O}_{3}$ & 22.7 \\
Anatase & $\mathrm{TiO}_{2}$ & 3.6 \\
Rutile & $\mathrm{TiO}_{2}$ & 0.7 \\
Zircon & $\mathrm{ZrO}_{2}$ & 0.2 \\
Goethite & $\mathrm{FeOOH}$ & 12.1 \\
Gibbsite & $\mathrm{Al}(\mathrm{OH})_{3}$ & 6.2 \\
DSP * & $\mathrm{Na}_{6}\left[\mathrm{Al}_{6} \mathrm{Si}_{6} \mathrm{O}_{24}\right] \mathrm{Na}_{2} \mathrm{X}$ & 7.9 \\
\hline SUM crystalline & & 57.1 \\
\hline SUM amorphous & & 42.9 \\
\hline * DSP = de-silication product (type of sodalite), where $\mathrm{X}=\mathrm{SO}_{4}{ }^{2-}, \mathrm{CO}_{3}{ }^{2-}, \mathrm{Cl}-, \mathrm{Al}(\mathrm{OH})_{4}-\mathrm{OH}^{-}$
\end{tabular}

$\mathrm{BR}$ is rich in iron oxide, alumina and silica and has a $\mathrm{Na}_{2} \mathrm{O}$ content of $9.6 \%$. The main crystalline phases are hematite, goethite, gibbsite and sodalite. Additionally, BR consists of about $43 \%$ X-Ray amorphous material which is probably mainly part of the desilication product (DSP) deriving from the production process. The median $\left(\mathrm{d}_{50}\right)$ value of the particle size distribution for BR, cement and limestone was $0.9,13.4$ and $16.1 \mu \mathrm{m}$, respectively. 


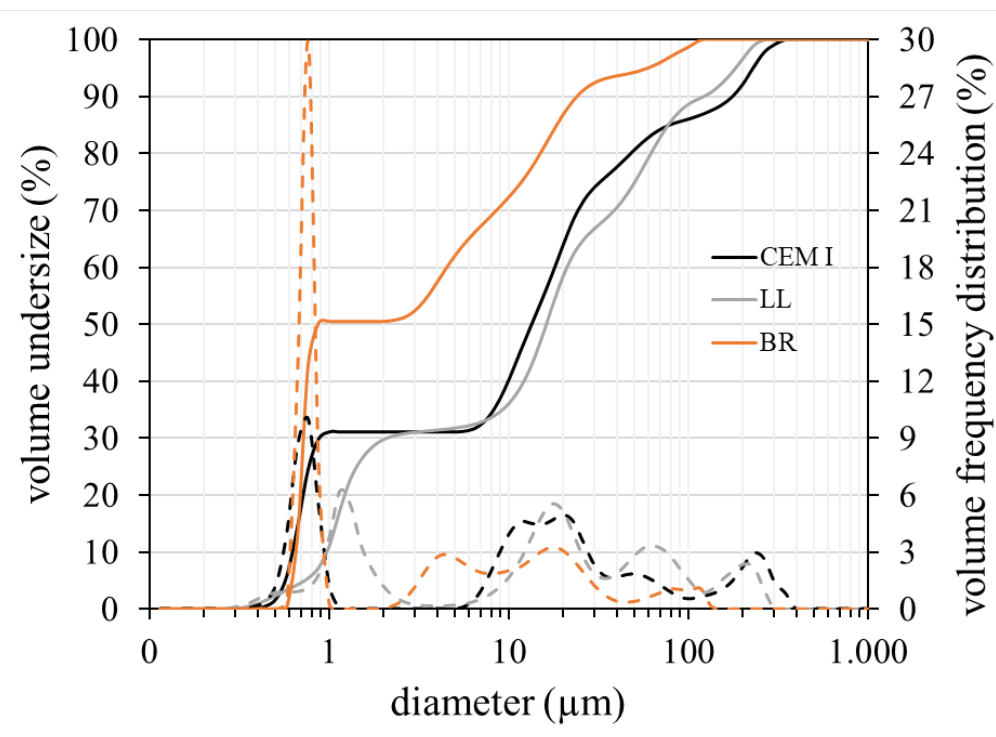

Figure 1 - Particle size distributions of cement (CEM I), limestone filler (LL) and bauxite residue (BR)

\section{EXPERIMENTAL}

The process of alkali reduction of BR was adapted based on the experiments performed in [20]. Moist BR "as received" was washed with $0.5 \mathrm{M}$ acetic acid in a ratio of acetic acid/dry BR = 10. Initial tests were performed on small scale $(50 \mathrm{~mL})$ centrifuge bottles, before upscaling to $1000 \mathrm{~mL}$ centrifuge bottles. The weighed in materials (BR and $0.5 \mathrm{M}$ acetic acid) were transferred to the centrifuge bottles and BR was kept in suspension by shaking the bottles several times within 24 hours. After 24 hours, the bottles were centrifuged for $5 \mathrm{~min}$ at 5000 rpm. After the acetic acid treatment, the sample was washed twice with water and centrifuged to remove the water. After each washing step a sample of the supernatant solution was taken for analysis of leaching with flame spectroscopy. Finally, the dried AR-BR was milled down with an auto-mortar (RETSCH RM 200) at highest pestle pressure for $5 \mathrm{~min}$, similar to the original BR. The procedure was to ensure a good removal of $\mathrm{Na}$ and not optimized in terms of required treatment time or temperature resembling industrial processing.

The chemical composition of PC, LL, BR and AR-BR was analysed with X-Ray Fluorescence $(X R F)$ with Bruker AXS S8 Tiger WDXRF with a $4 \mathrm{~kW}$ generator, using molten glass disks.

Qualitative $X$-ray diffraction (XRD) was performed on a Bruker D8 Focus instrument equipped with a Lynx Eye detector and a $\mathrm{Cu}-\mathrm{K} \alpha \mathrm{X}$-Ray source. A $0.2 \mathrm{~mm}$ divergence slit was used, and measurements were taken from $5-75^{\circ} 2 \theta$ with a step size of $0.2^{\circ} 2 \theta$ and $0.8 \mathrm{~s}$ time per step. Quantitative mineralogical analysis was performed by Rietveld analysis using the Topas Software version 4.2 and the ICDD PDF4+ mineral structure database. Quantification of amorphous content was done by the external standard method also called "G-factor method" in some places [15-17], by using an external quartzite standard. The quartzite was calibrated against a silicon powder from NIST (Standard Reference Material 640d) [15]. 
Thermogravimetric analysis (TGA) was performed with a Mettler Toledo TGA/SDTA 851. Samples were analysed with a heating rate of $10^{\circ} \mathrm{C} / \mathrm{min}$ between 40 and $900^{\circ} \mathrm{C}$. All measurements were performed in nitrogen atmosphere with a flow rate of $50 \mathrm{ml} / \mathrm{min}$. The calcium hydroxide $(\mathrm{CH})$ consumption and bound water in pastes were calculated from the weight loss between $\sim 400$ and $550^{\circ} \mathrm{C}$ and 40 and $350^{\circ} \mathrm{C}$, respectively. The exact boundaries for $\mathrm{CH}$ consumption were chosen from the peak in the DTG curve.

Particle size distribution (PSD) was measured with a Horiba Partica LA-960. Dry cement powders were immersed in isopropanol combined with ultrasonic treatment for $1 \mathrm{~min}$ to deagglomerate particles.

Cement pastes were mixed with $20 \%$ replacement of cement by either limestone filler, BR or AR-BR. Additional pastes were prepared by replacing $25 \%$ cement with $20 \%$ BR or AR-BR and $5 \%$ limestone filler. The hydration kinetics were studied at $20^{\circ} \mathrm{C}$ with isothermal calorimetry using a TAM AIR calorimeter. Pastes were prepared by external mixing. $8 \mathrm{~g}$ of binder was mixed with $4.8 \mathrm{~g}$ of water $(\mathrm{w} / \mathrm{b}=0.6)$. Materials were weighed into a sample flask and water was weighed in a syringe. After adding the water, the pastes were shaken (mixed) with a Vortex SA6 at $4500 \mathrm{rpm}$ for $1 \mathrm{~min}$. The samples were taken out of the calorimeter after 28 days, and hydration was stopped by solvent exchange according to [21]. The samples were then milled down by hand to fine powder and prepared for XRD and TGA analysis.

Mortars were mixed and cast according to NS EN 196-1 for measurement of compressive and flexural strength after 1, 3 and 28 days. Mortars were mixed with a water to binder ratio $(\mathrm{w} / \mathrm{b})$ of 0.5 . The ratio between binder and norm sand (DIN) was $1 / 3$. Besides a reference with $100 \%$ cement, mortars were cast with $20 \%$ replacement of cement (by weight) with LL, BR and ARBR. Water and cement were added to the cement bowl and mixed for $30 \mathrm{~s}$ at low speed. Sand was added during the next $30 \mathrm{~s}$ and the mixture was mixed at high speed for further $30 \mathrm{~s}$. After $90 \mathrm{~s}$ in resting position the mixture was mixed for another $60 \mathrm{~s}$ at high speed. Before casting the mortars into standard RILEM mortar prisms $(40 \times 40 \times 160 \mathrm{~mm})$, the flow (spread) was measured according to EN 413-2. After 24 hours the prisms were demoulded and stored at $20^{\circ} \mathrm{C}$ and $90 \%$ relative humidity $(\mathrm{RH})$ until the age of testing.

Another set of mortars was cast for extraction of pore solution after 28 and 91 days of curing. The same mixing design and procedure was used with the exception that the w/c was increased to 0.66 to guarantee enough pore solution to be extracted. The mortars were cast into cylindrical plastic bottles $(125 \mathrm{~mL})$ and cured at 20 and $38^{\circ} \mathrm{C}$. At the age of testing the samples were removed from the bottles by cutting the top and the bottom of the cylinder. The investigated samples had a height of about $65 \mathrm{~mm}$ and a diameter of $45 \mathrm{~mm}$. Pore solution was obtained by high-pressure pore water expression (PWE) as described in [22]. The applied pressure was about $350 \mathrm{kN}$. The expressed solution was filtered and analysed for $\mathrm{pH}$ as well as $\mathrm{Na}$ and $\mathrm{K}$ content by flame spectroscopy. 
Table 3 shows the results of sodium ( $\mathrm{Na}$ ) analysis in solution after washing BR with acetic acid and subsequently with water. After washing with acetic acid, $5650 \mathrm{mg} / \mathrm{L} \mathrm{Na}$ was measured in the solution which was calculated to be equivalent to an almost $80 \%$ reduction of $\mathrm{Na}_{2} \mathrm{O}$ from the initial untreated BR. Further washing with water released residual $\mathrm{Na}$, resulting in a theoretical total $\mathrm{Na}_{2} \mathrm{O}$ reduction of $91 \%$. Quantitative XRF analysis (Table 4) confirmed the considerable decrease of $\mathrm{Na}_{2} \mathrm{O}$ in the acetic acid treated material. In a pre-investigation to this paper, a $\mathrm{Na}_{2} \mathrm{O}$ reduction to $<1 \%$ was achieved ( $\sim 91 \%$ reduction). Upscaling of the acetic acid treatment for hydration studies in bigger test tubes resulted in a reduction from 9.6 to $1.7 \%$ ( $\sim 83 \%$ reduction). This shows that the acetic acid treatment can be further optimized to maximise alkali reduction. Due to washing out of some components from BR, some oxides (e.g. $\mathrm{Fe}_{2} \mathrm{O}_{3}$ ) show increased values in AR-BR. Besides $\mathrm{Na}_{2} \mathrm{O}$ it seems that some minor amounts of silica, alumina and calcium oxide were washed out as well. The reason is most likely the structural breakdown of sodalite and other alkaline minerals of the desilication product by hydrolysis [20].

Table 3 - Results of flame spectroscopy measurements of Na washed out by acetic acid treatment and washing with water; and calculated amount of total $\mathrm{Na}_{2} \mathrm{O}$ reduction.

\begin{tabular}{ccc}
\hline & $\begin{array}{c}\text { Na in solution } \\
(\mathrm{mg} / \mathrm{L})^{1}\end{array}$ & $\begin{array}{c}\text { Total } \mathrm{Na}_{2} \mathrm{O} \text { reduction } \\
(\%)\end{array}$ \\
\hline Acetic acid $^{2}$ & 5650 & $79.3 \%$ \\
$\mathrm{H}_{2} \mathrm{O}_{1}{ }^{4}$ & 632 & $88.4 \%$ \\
$\mathrm{H}_{2} \mathrm{O}_{2}{ }^{4}$ & 190 & $91.2 \%$ \\
\hline
\end{tabular}

${ }^{1}$ Amount of Na measured by flame spectroscopy in filtrate solution

${ }^{2}$ Theoretical amounts of $\mathrm{Na}_{2} \mathrm{O}$ reduction calculated by mass balance

${ }^{3}$ Acetic acid washing

4 Two steps of washing with water, see (Chapter 3)

Table 4 - XRF analysis of dried untreated bauxite residue (BR) compared to alkali reduced bauxite residue (AR-BR)

\begin{tabular}{lccc}
\hline Oxides & BR & $\begin{array}{c}\text { AR-BR_sb } \\
\text { (Weight } \%)\end{array}$ & AR-BR_bb ${ }^{2}$ \\
\hline $\mathrm{CaO}$ & 1.7 & 0.2 & 0.3 \\
$\mathrm{SiO}_{2}$ & 16.0 & 14.0 & 15.8 \\
$\mathrm{Al}_{2} \mathrm{O}_{3}$ & 18.9 & 15.1 & 16.0 \\
$\mathrm{Fe}_{2} \mathrm{O}_{3}$ & 37.9 & 49.0 & 42.8 \\
$\mathrm{TiO}_{2}$ & 6.2 & 8.0 & 7.0 \\
$\mathrm{MgO}$ & $<0.1$ & $<0.1$ & $<0.1$ \\
$\mathrm{~K}_{2} \mathrm{O}$ & 0.1 & $<0.1$ & $<0.1$ \\
$\mathrm{Na}_{2} \mathrm{O}$ & 9.6 & 0.9 & 1.7 \\
$\mathrm{LOI}$ & 7.8 & 10.7 & 13.2 \\
\hline $\mathrm{SUM}$ & 98.6 & 98.3 & 97.0 \\
\hline
\end{tabular}

${ }^{1}$ Small batch $(50 \mathrm{~mL}$ centrifuge bottles) from pre-investigation on alkali reduction potential

${ }^{2} \mathrm{Big}$ batch (1000 $\mathrm{mL}$ centrifuge bottles) used for hydration studies in this paper

The destruction of sodalite was confirmed by X-Ray analysis (Figure 2). The main peaks of sodalite disappeared in AR-BR while the main peaks of hematite, goethite and gibbsite were unaffected by the acetic acid treatment. Ion exchange reaction of $\mathrm{Na}^{+}$with $\mathrm{H}^{+}$in the desilication 
product, hydrolysis of Al- and Si species and organic surface complexation (chelation reactions) [20] might be responsible for the higher LOI value of AR-BR besides the same drying conditions before analysis. It is worth noting that aluminium triacetate will hydrolyse in water to aluminium diacetate hydroxide (so called basic aluminium acetate) that is insoluble. Iron (+III) acetate as potential product or surface complex during acetic acid treatment is also insoluble in water. Particle size distribution analysis (Figure 3) shows that AR-BR has higher amounts of coarser particles, probably due to agglomeration. The median particle size $\left(\mathrm{d}_{50}\right)$ of AR-BR was $14.8 \mu \mathrm{m}$ compared to $0.9 \mu \mathrm{m}$ of BR. Coarser particle structure and the formation of macro-aggregates in bauxite residue de-alkalized with different mineral acids was also observed by others $[23,24]$.

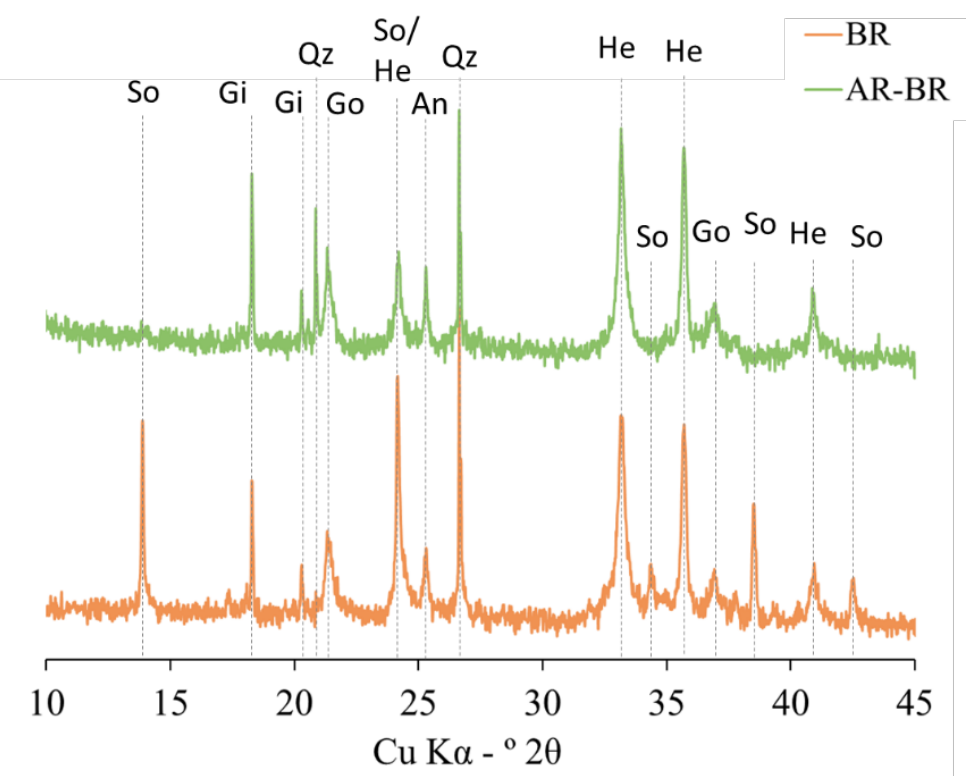

Figure $2-X$-Ray analysis of dried untreated bauxite residue (BR) and alkali reduced bauxite residue $(A R-B R)$. So = sodalite, $G i=$ gibbsite, $Q z=$ quartz, Go = goethite, He = hematite, $A n$ = anatase

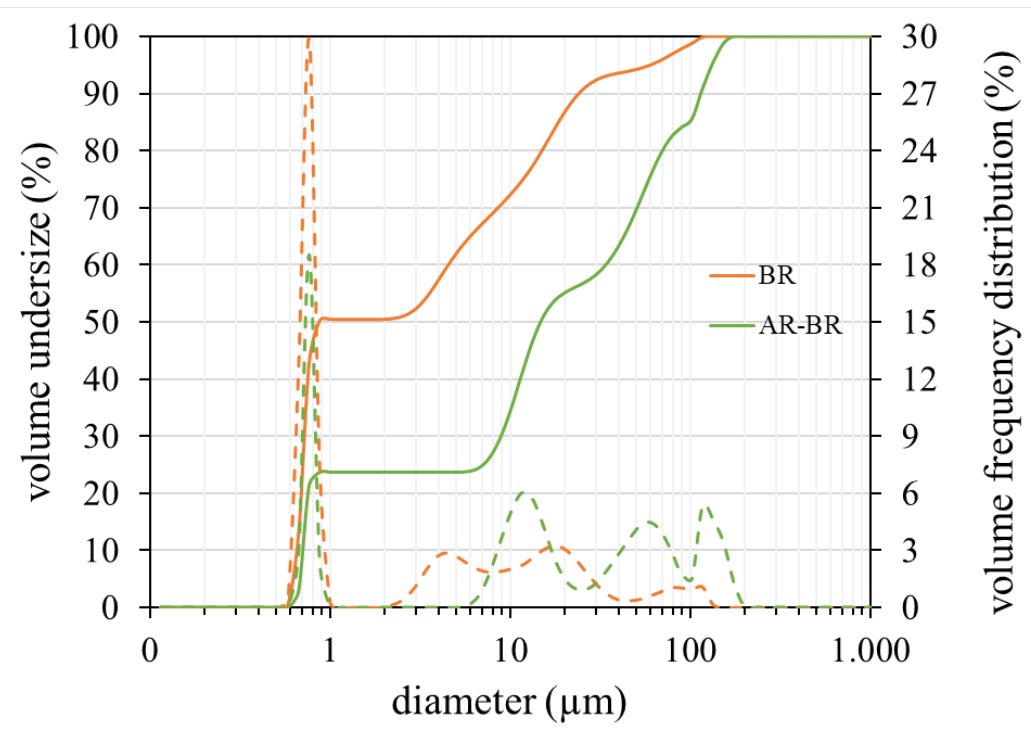

Figure 3 -Particle size distributions of dried untreated bauxite residue (BR) and alkali reduced bauxite residue (AR-BR) 
The hydration kinetics of cement pastes with $20 \%$ replacement of cement by untreated bauxite residue (BR) and acetic acid treated, i.e. alkali reduced bauxite residue (AR-BR), were studied with isothermal calorimetry. The results are presented as measured and normalized to the amount of cement (Figure 4). The thermal power curve of the reference cement pastes show the typical hydration kinetics of ordinary Portland cements with the peak of the main silicate $\left(\mathrm{C}_{3} \mathrm{~S}\right)$ hydration reaction in the acceleration period and the shoulder peak with the renewed $\mathrm{C}_{3} \mathrm{~A}$ dissolution and secondary formation of ettringite [25]. The heat release with $20 \%$ limestone filler is slightly higher and accelerated due to the filler effect [26]. The main hydration peak is also slightly wider compared to the reference cement paste without SCM. The addition of BR and AR-BR accelerate and enhance the hydration of $\mathrm{C}_{3} \mathrm{~S}$ and thus the formation of C-S-H phases to a higher degree than limestone. This can be ascribed to the additional provided nucleation sites for hydration products to form and potentially increased shearing of the cement particles during mixing [25] by stable mineral phases like hematite in BR and AR-BR. For both $\mathrm{BR}$ and AR-BR the heat release in the induction period is increased. Pastes with AR-BR show the highest heat release in the induction period. However, the silicate reaction is less accelerated and enhanced and the main peak of $\mathrm{C}_{3} \mathrm{~S}$ reaction is also less wide compared to reference pastes and pastes with BR. Setting (onset of acceleration period) seems also to be delayed with ARBR.

For pastes with BR the shoulder peak of renewed ettringite formation is less pronounced. A broader peak can be observed after around $70 \mathrm{~h}$ of hydration which is most likely associated with the formation of AFm phases. In pastes with AR-BR a broader peak can be observed around 25-30 h of hydration, indicating accelerated AFm phase formation in comparison to pastes with BR. Minor amounts of acetic acid potentially left in AR-BR particles might contribute to the slightly delayed setting but accelerated formation of AFm phases [27].

The hydration kinetics were followed up to 4 weeks in the calorimeter, but no further peaks were observed in the thermal power curve after 3-4 days of hydration. The higher degree of hydration acceleration with BR might be due to the smaller particle sizes and thus larger surface provided. Furthermore, the higher alkali content in BR might contribute to increased acceleration of the cement hydration. Extra addition of 5\% limestone to pastes with BR and AR-BR did not change the early (first $24 \mathrm{~h}$ ) hydration kinetics. The cumulative heat was however increased in pastes containing limestone compared to the pastes without limestone, possibly due to the slower formation of calcium hemi- and mono-carboaluminate and potential reformation of ettringite by sulphate released from AFm in this process.

Within the first 24 hours of hydration, common SCMs like fly ash or slag are not yet reacting and the impact on hydration kinetics is comparable to the addition of inert quartz powder as presented in [26]. Here, there is a clear difference in hydration kinetics between pastes with limestone and the pastes with BR and AR-BR. This indicates that BR and especially AR-BR, which has a similar particle size distribution compared to limestone and cement, might have an additional chemical or physical effect at early age besides acting as additional nucleation sites. The mechanisms of hydration will be further studied in future investigations on the utilization of AR-BR as SCM. 

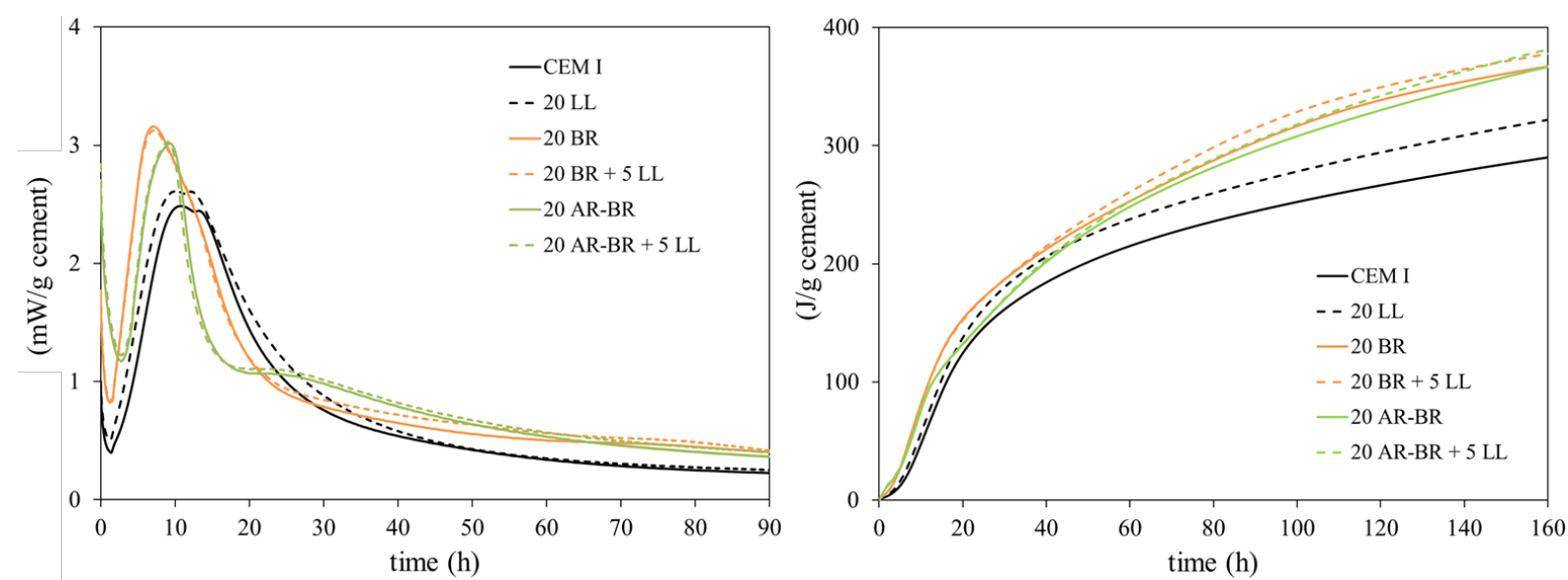

Figure 4 - Isothermal calorimetry of cement pastes with LL, BR and AR-BR. Left: Thermal power; Right: Cumulative heat development

Figure 5 shows the XRD diffractograms of the cement pastes after hydration for 28 days. On the right side the portlandite $(\mathrm{CH})$ peak is shown. The reduction in the amount of portlandite is a qualitative measure of the pozzolanic reactivity of a SCM. Limestone is not pozzolanic and the reduction of the portlandite peak is due to the dilution of the cement paste, i.e. lower amount of $\mathrm{C}_{3} \mathrm{~S}$ and $\mathrm{C}_{2} \mathrm{~S}$ to produce $\mathrm{CH}$. In pastes with $\mathrm{BR}$ and AR-BR a considerable reduction is observed, much more than what a simple $20 \%$ reduction of cement should impose. It is clear that both BR and AR-BR are pozzolanic in nature, reacting with $\mathrm{CH}$ to form further hydration products. The degree of pozzolanic reactivity of BR and AR-BR seems to be about similar. The reactivity of BR was earlier proven to be higher than fly ash [15] with the R3 test [28]. The pozzolanic reaction of $\mathrm{BR}$ and AR-BR results in the increased formation of AFm hydration products as can be seen on the left side of Figure 5. In pastes with BR and AR-BR, ettringite is slightly reduced while the amount of carboaluminate hydrate phases is considerably increased. With the addition of BR and AR-BR mainly calcium hemi-carboaluminate hydrate is formed. Extra addition of 5\% limestone favours the formation of calcium mono-carboaluminate hydrate.
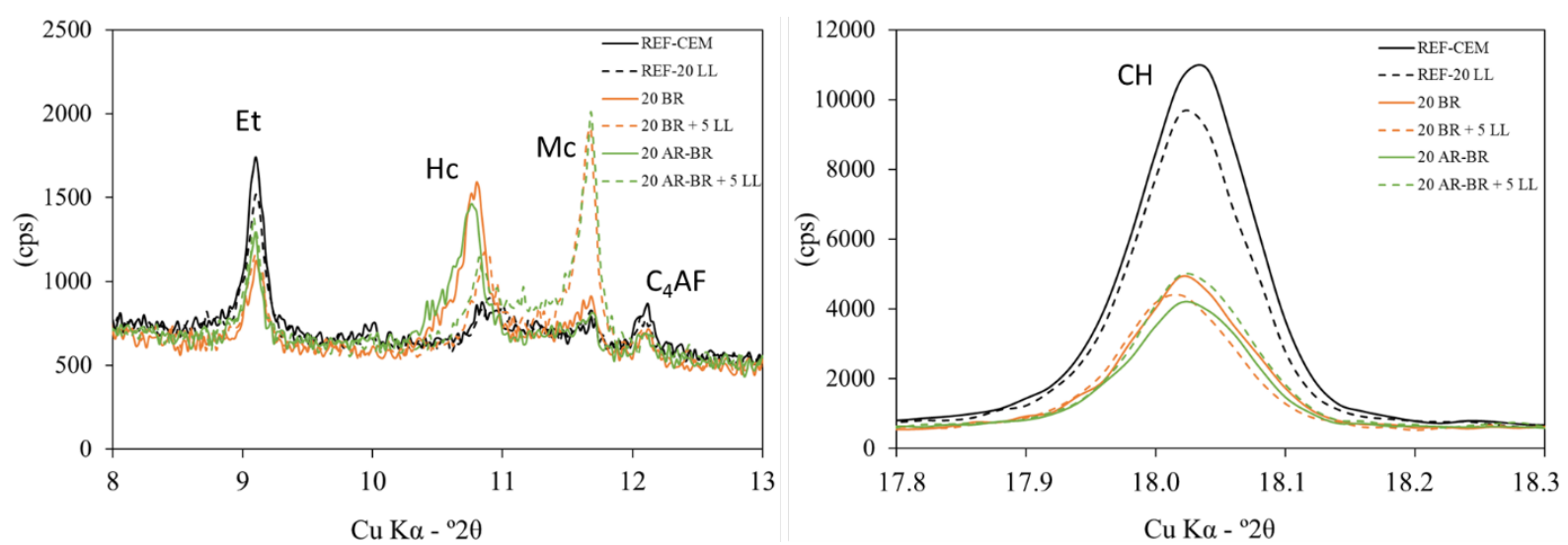

Figure $5-X R D$ curves of cement pastes with $L L, B R$ and AR-BR after 28 days of hydration. Left: Area of AFt $(E t=$ Ettringite $)$ and AFm phases (Hc = calcium hemi-carboaluminate hydrate, $M c=$ calcium mono-carboaluminate hydrate), as well as $C_{4} A F=$ tetracalcium aluminoferrite clinker phase, Right: Main Portlandite ( $\mathrm{CH}$ - calcium hydroxide) peak.

The results of pozzolanic reactivity by decreased amounts of $\mathrm{CH}$ and increased amounts of AFm phase formation are confirmed by TGA analysis (Figure 6). The amounts of calculated 
bound water in the $\mathrm{C}-\mathrm{S}-\mathrm{H}, \mathrm{AFt}$ and $\mathrm{AFm}$ phase region $\left(40-400^{\circ} \mathrm{C}\right)$ and the amount of $\mathrm{CH}$ are given in Table 5. The error of TGA measurements is in the region $\pm 1 \%$. Compared to the reference cement paste, $20 \%$ addition of $\mathrm{BR}$ and $\mathrm{AR}-\mathrm{BR}$ result in an increased amount of bound water due to increased formation of AFm phases and maybe C-S-H phases. There was no difference in bound water with extra addition of limestone. However, the amount of $\mathrm{CH}$ was further decreased with extra addition of limestone which might in parts reflect the further dilution of the cement paste.
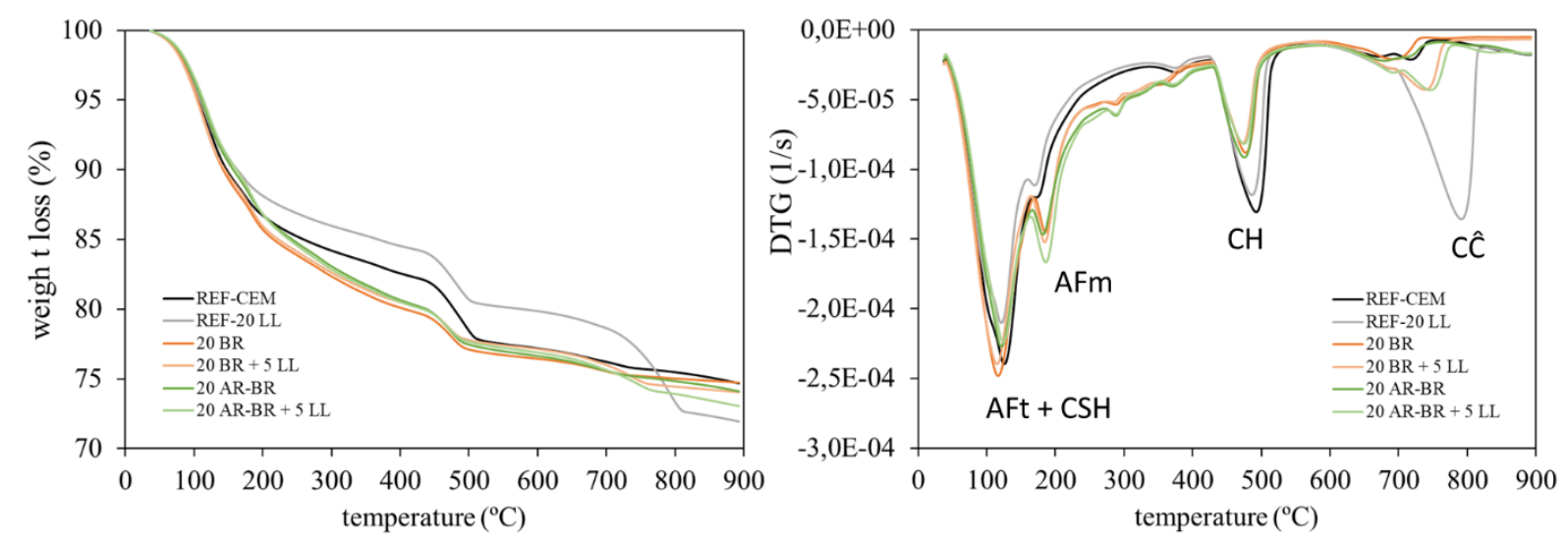

Figure 6 - Thermogravimetric analyses of cement pastes with LL, BR and AR-BR after 28 days of hydration. Left: TGA curves (thermogravimetry), Right: DTG curves (differential thermogravimetry)

Table 5 - Bound water, Calcium hydroxide content $(\mathrm{CH})$ and calcite content calculated from TG/DTG curves after 28 days

$$
\begin{gathered}
\text { Bound water }{ }^{0-400^{\circ} \mathrm{C}} \mathrm{CH}^{400-550^{\circ} \mathrm{C}} \\
\left(\% \text { by dry weight at } 550^{\circ} \mathrm{C}\right)
\end{gathered}
$$

\begin{tabular}{ccc}
\hline REF CEM I & 21.1 & 28.3 \\
20 LL & 18.3 & 23.6 \\
20 BR & 24.9 & 19.1 \\
20 BR +5 LL & 24.2 & 17.2 \\
20 AR-BR & 24.0 & 20.6 \\
20 AR-BR + 5 LL & 24.2 & 18.4 \\
\hline
\end{tabular}

The compressive strength of mortars with $20 \%$ replacement of cement by LL, BR and AR-BR after 1, 3 and 28 days of hydration is given in Figure 7. At all ages, the reference cement mortar had the highest compressive strength. After 24 and 72 hours of hydration the compressive strength of mortars with $20 \%$ BR was close to the reference. The mortar with $20 \%$ AR-BR had the lowest compressive strength after 24 hours, even lower than the mortar with $20 \%$ limestone. Limestone powders seem to have a unique additional effect on early hydration compared to other SCMs and inert materials. Microstructural investigations indicated preferential nucleation of C-S-H on limestone surfaces which was not observed for other SCMs or inert quartz powder [26]. This explains the good contribution to 24 hours strength. The low early strength ( 24 hours) with AR-BR is in line with the inflection of cumulative heat at early age and the narrow peak in the acceleration period of the thermal power curve. The faster hydration of mortars with BR compared to mortars with AR-BR is potentially due to the higher alkalinity and the finer particle 
sizes. Furthermore, residual acetate potentially adsorbed on the surfaces of AR-BR particles might be released upon contact with high $\mathrm{pH}$ from the cement and inhibit early strength development.

After 3 days the compressive strength with AR-BR was higher compared to the mortar with limestone but still less compared to the mortar with BR. Between 3 to 28 days, mortars with BR had the lowest relative strength increase and the 28-day strength was lower than the strength of the limestone mortar. After 28 days of hydration the mortar with AR-BR had the highest compressive strength of the three SCM's and the strength was about $90 \%$ of the reference mortar strength without cement replacement. The strength development of mortars with BR, high early strength and low 28 day strength, is explained by the high alkali content and was already observed in earlier investigations [15, 29]. Addition of BR and AR-BR increased the water demand of the mortars and the measured flow (spread) was reduced by 10 and $17 \%$, respectively, compared to the reference cement. However, all mortars were castable without plasticizers and there was no significant difference in the weight of the mortars after demoulding. There was furthermore no visual difference in the degree of compaction or amount of air voids between the different mortars.

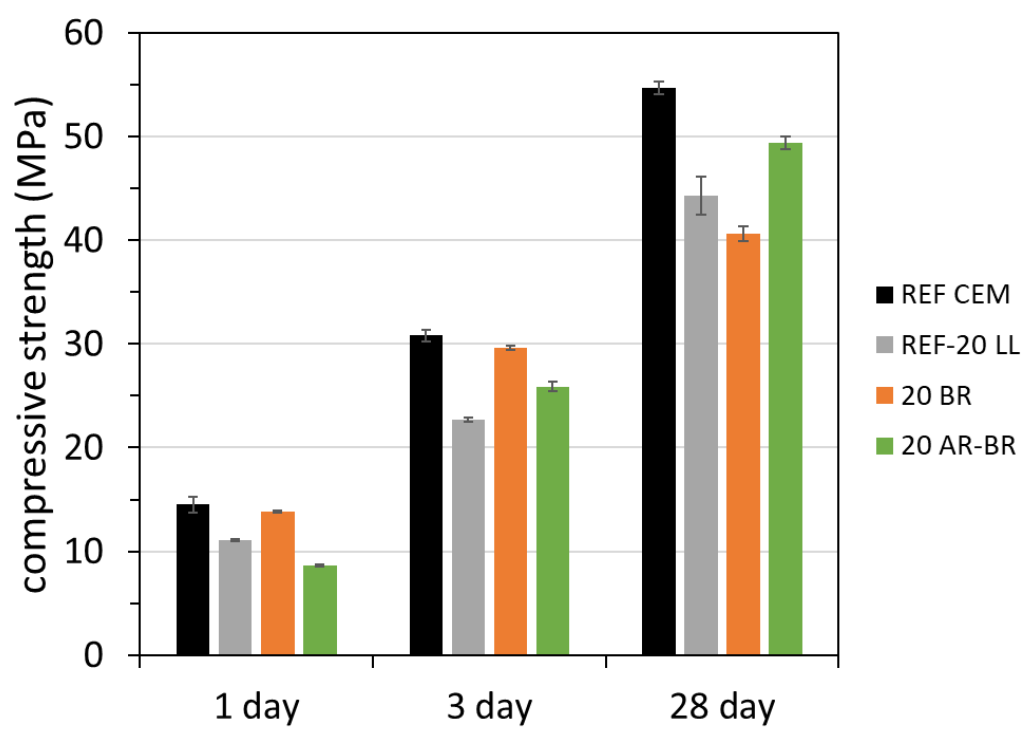

Figure 7: Compressive strength of mortars with 20\% cement replacement by LL, BR and AR$B R$

The results show that AR-BR has good pozzolanic reactivity showing satisfying contribution to 28-day compressive strength development of mortars. Besides removing the high amount of alkalis, the main reactive components appear not to have been washed out of BR. This may be due to the insolubility of aluminium diacetate hydroxide (so called basic aluminium acetate) and iron (+III) acetate potentially forming as products or surface complexes during acetic acid treatment of BR. Further investigations on the optimization of early strength and workability by applying admixtures and sulphate optimization will be performed in a future project.

Table 6 shows the results of the pore water analysis of mortars after curing for 28 days at 20 and $38^{\circ} \mathrm{C}$. The $\mathrm{pH}$ of the pore solution of mortars with AR-BR was similar or slightly lower compared to the $\mathrm{pH}$ of the reference mortar without cement replacement, while the $\mathrm{pH}$ of 
mortars with untreated BR was increased. The amount of $\mathrm{Na}$ in the pore solution was significantly reduced when AR-BR is used instead of BR as cement replacement. However, the $\mathrm{Na}$ content was still relatively high compared to the reference mortar and the mortar containing limestone filler, which could have implications for AAR. In future studies the alkali-reduction process will be optimized to obtain a constant and low $\mathrm{Na}_{2} \mathrm{O}$ content $(<1 \%)$ in AR-BR in the shortest possible time. The potential impact of AR-BR on AAR will be investigated in more detail.

Mortars for PWE and consequent analysis pore water were mixed with a w/b of 0.66 . Visually it was observed excess water due to segregation on top of the samples CEM I and $20 \mathrm{LL}$ after curing, while all water was bound in samples BR and AR-BR. Hence, mortars with AR-BR and BR bound more water than the reference mortars as it was also measured in pastes (Table 5). This could result in an increased concentration of alkalis in the pore water of mortars with AR$\mathrm{BR}$ and $\mathrm{BR}$.

Table 6: Pore water analysis of mortars after hydration for 28 days

\begin{tabular}{ccccccc}
\hline & \multicolumn{2}{c}{$\mathrm{pH}$} & \multicolumn{2}{c}{$\mathrm{Na}(\mathrm{mg} / \mathrm{L})$} & \multicolumn{2}{c}{$\mathrm{K}(\mathrm{mg} / \mathrm{L})$} \\
\hline Hydration temperature $\left({ }^{\circ} \mathrm{C}\right)$ & 20 & 38 & 20 & 38 & 20 & 38 \\
\hline CEM I & 13.26 & 13.27 & 2600 & 3100 & 5300 & 5400 \\
Bleeding water & 13.20 & 13.19 & 1600 & 1800 & 4100 & 4300 \\
\hline 20 LL & 13.18 & 13.22 & 2200 & 2500 & 4000 & 4100 \\
Bleeding water & 13.13 & 13.15 & 1500 & 1700 & 3300 & 3500 \\
\hline 20 BR & 13.34 & 13.35 & 20250 & 21500 & 3250 & 3250 \\
\hline 20 AR-BR & 13.25 & 13.18 & 7300 & 7500 & 4400 & 4400 \\
\hline
\end{tabular}

5. PERSPECTIVES

\subsection{Sustainable waste management and production of AR-BR as novel SCM}

Currently, bauxite is mined and treated in the Bayer process to produce $\mathrm{Al}_{2} \mathrm{O}_{3}$ and large amounts of bauxite residue hazardous waste ending up in disposal sites. Treatment of BR with acetic acid can potentially alter this linear process to a partly circular process (Figure 8). First of all, implementation of acetic acid treatment of BR at alumina plants will result in a low alkali BR (AR-BR) and allow the re-use of a major waste stream produced in global volumes of about 175 million tonnes annually. Besides transforming BR to a non-hazardous waste material that can find application as SCM, the suggested process below has in theory even more advantages, e.g. maximizing the amount of recovered caustic soda for the Bayer process. Acetic acid will remove $\mathrm{Na}_{2} \mathrm{O}$ from $\mathrm{BR}$, resulting in the formation of a Na-acetate solution. Drying the solution will result in precipitation of Na-acetate which can potentially be sold as non-corrosive de-icing salt [34]. On the other hand, parts of the sodium acetate could be decomposed thermally at relatively low temperature to form pure $\mathrm{Na}_{2} \mathrm{O}$ for production of caustic soda ( $\mathrm{NaOH}$ solution). The regained caustic soda can be used directly further in the Bayer process to produce more alumina and BR and minimizing the loss of sodium hydroxide. This will close the cycle and increase the sustainability of the proposed process (Figure 8). During the thermal decomposition of sodium acetate to sodium oxide an organic compound will also be formed 
that might be used for certain applications. If it is acetic anhydride, it may be used to regenerate acetic acid in reaction with water, further closing the loop. These potential positive side effects will be further investigated in future projects.

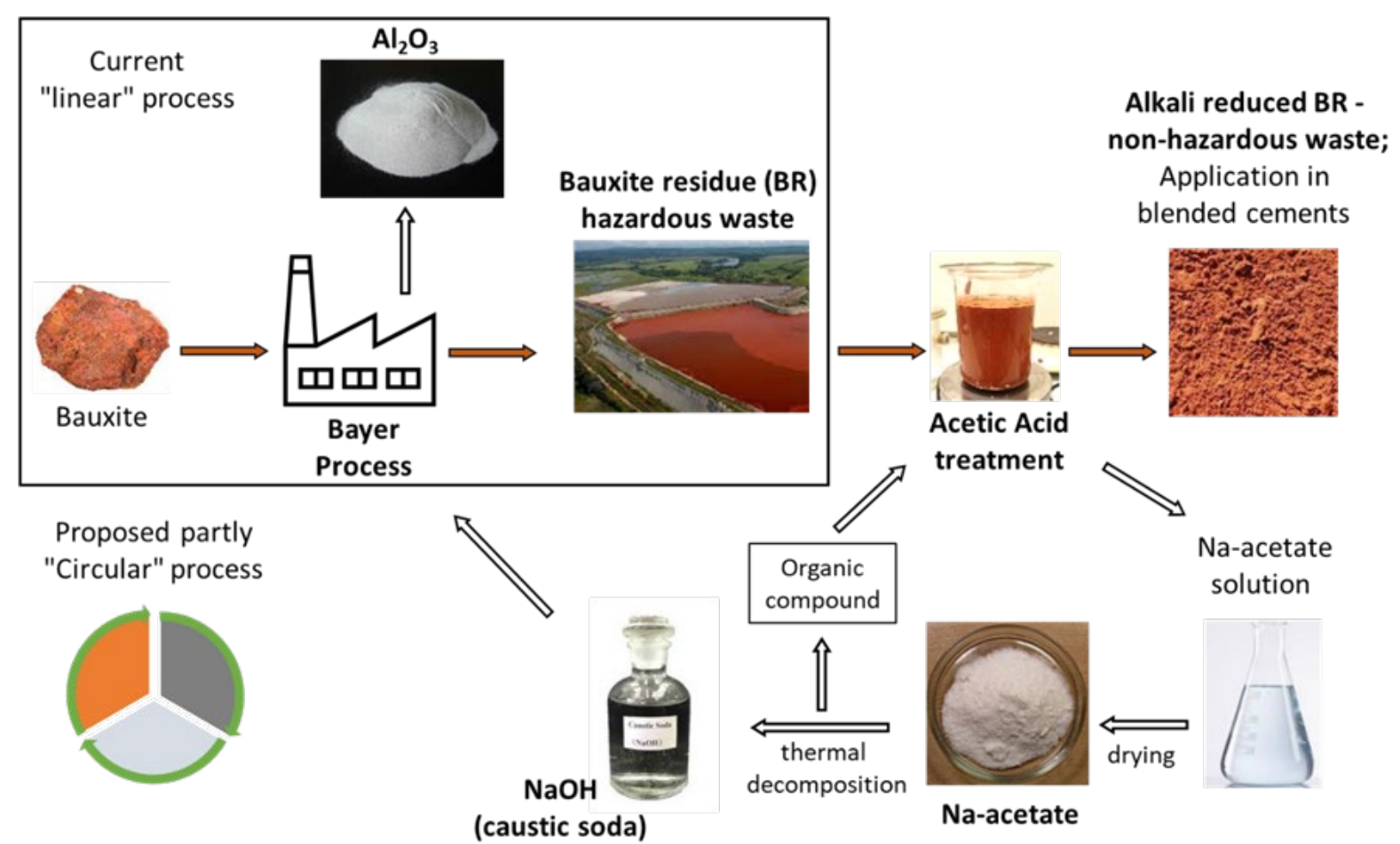

Figure 8 - Scheme of underlying idea for sustainable waste management of BR and the production of alkali reduced BR to be used as supplementary cementitious material for cement.

It is possible that the thermal decomposition of sodium acetate to sodium oxide and acetic anhydride must be carried out under a blanket of recycled inert gas like nitrogen;

$2 \mathrm{NaCH}_{3} \mathrm{COO}=\mathrm{Na}_{2} \mathrm{O}(\mathrm{s})+\left(\mathrm{CH}_{3} \mathrm{CO}\right)_{2} \mathrm{O}(\mathrm{g})$

Followed by separate treatment with water;

$\mathrm{Na}_{2} \mathrm{O}+\mathrm{H}_{2} \mathrm{O}=2 \mathrm{NaOH}(\mathrm{aq})$

$\left(\mathrm{CH}_{3} \mathrm{CO}\right)_{2} \mathrm{O}(\mathrm{g})+\mathrm{H}_{2} \mathrm{O}=2 \mathrm{CH}_{3} \mathrm{COOH}(\mathrm{aq})$

However, should the thermal degradation product of sodium acetate be sodium carbonate (e.g. presence of air or $\mathrm{CO}_{2}$ ), this can easily be converted to sodium hydroxide using a lime cycle;

$\mathrm{Na}_{2} \mathrm{CO}_{3}(\mathrm{aq})+\mathrm{Ca}(\mathrm{OH})_{2}=2 \mathrm{NaOH}(\mathrm{aq})+\mathrm{CaCO}_{3}(\mathrm{~s})$

Precipitated calcium carbonate is filtered off and thermally decomposed to calcium oxide at $900^{\circ} \mathrm{C}$;

$\mathrm{CaCO}_{3}(\mathrm{~s})=\mathrm{CaO}(\mathrm{s})+\mathrm{CO}_{2}(\mathrm{~g})$ followed by $\mathrm{CaO}+\mathrm{H}_{2} \mathrm{O}=\mathrm{Ca}(\mathrm{OH})_{2}$ 
The production of sodium acetate salt was confirmed by drying the solution after the acetic acid treatment of BR and qualitative investigation with XRD (Figure 9). The red colour of the sodium acetate salt is probably due to impurities of iron oxides. Filtration of the sodium acetate solution before drying will most likely result in a less intensive colouration of the salt.

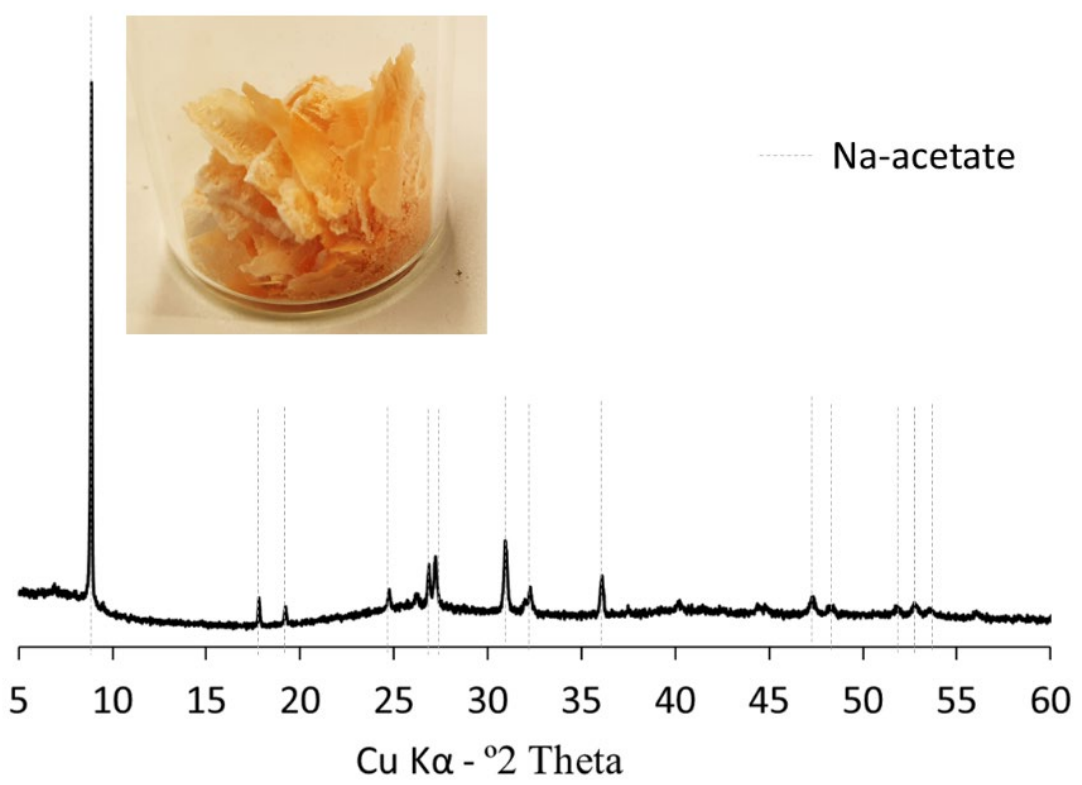

Figure 9 - Picture of sodium acetate produced by drying the solution after the acetic acid treatment of $B R$ and XRD diffractogram of the milled powder.

After acetic acid treatment of BR, minor amounts of sodium acetate might be left on the surfaces of AR-BR. However, sodium acetate was not reported to have a negative effect on concrete strength and durability. In fact, integrating sodium acetate in concrete was shown to enhance durability by reducing permeability and extend the service life without affecting the strength [35]. The positive effect was also observed for curing under extreme environmental conditions, i.e. cold and hot climate [36] which is an advantage for the potential application of AR-BR as SCM in e.g. Norway or Brazil. Depending on the water to cement ratio, the curing conditions and the percentage of added Na-acetate, the water absorption of concrete decreased or increased [36]. Reduced permeability and decreased water absorption and hence decreased availability of moisture in pores might support potential AAR mitigation.

$75 \%$ of acetic acid are produced by carbonylation of methanol and methanol is produced by hydrogenation of carbon monoxide. All chemical elements for this process are easily available. In 2018, 18 million metric tonnes of acetic acid were produced. If BR treatment should increase the demand of acetic acid above today's market, it should hence be easy to scale up the production. The prize for acetic acid seems currently to be around 500-600 USD/ton for $>20$ tons order packed and might become cheaper when ordered in larger volumes.

Based on stochiometric calculations and assuming 1 ton of BR contains $100 \mathrm{~kg} \mathrm{Na} 2 \mathrm{O}$, about $175 \mathrm{~kg}$ acetic acid would be needed to get a $90 \%$ reduction in $\mathrm{Na}_{2} \mathrm{O}$. By further optimizing the process, the amounts of acetic acid needed might be reduced. Na-acetate sells for 900-1000 USD per ton. Assuming $80 \mathrm{~kg} \mathrm{Na} 2 \mathrm{O}$ are leached out per ton BR would result in $212 \mathrm{~kg} \mathrm{Na}-$ acetate that can be sold for about 200 USD. The cost of $155 \mathrm{~kg}$ acetic acid required is about 85 
USD, meaning that the proposed process also can have both economic and ecological advantages if implemented in Bayer plants.

\section{2}

\section{Application of AR-BR in aluminium reinforced concrete}

The DARE2C concept (Durable Aluminium Reinforced Environmentally-friendly Concrete Construction) is in detail described in [37]. The basic idea is to develop a concrete with lower $\mathrm{pH}$ that allows for aluminium to be used as reinforcement instead of regular steel.

The results of this work indicate that AR-BR has good pozzolanic activity and could be used as $\mathrm{SCM}$ in low $\mathrm{pH}$ concrete, enabling aluminium reinforcement for special applications. To proof the suitability of AR-BR for the DARE2C concept a simple experiment was conducted casting an aluminium rod in a low $\mathrm{pH}$ binder. The binder consisted of 50\% AR-BR, 41\% low alkali sulphate resistant cement, $4 \%$ gypsum and $3 \%$ limestone filler by weight. The water to binder ratio was 0.55 . The aluminium reinforced binder was cast into a $125 \mathrm{~mL}$ plastic bottle and sealed to avoid drying out. After about 1-month curing, the binder was removed from the plastic bottle. There were no signs of cracks or holes in the surface indicating no expansion due to corrosion or potential hydrogen gas evolution. Consequently, the sample was split. The bonding between the binder and the aluminium rod appeared to be good, and there were no signs of aluminium corrosion at the rod or at its imprint in the binder (Figure 10).

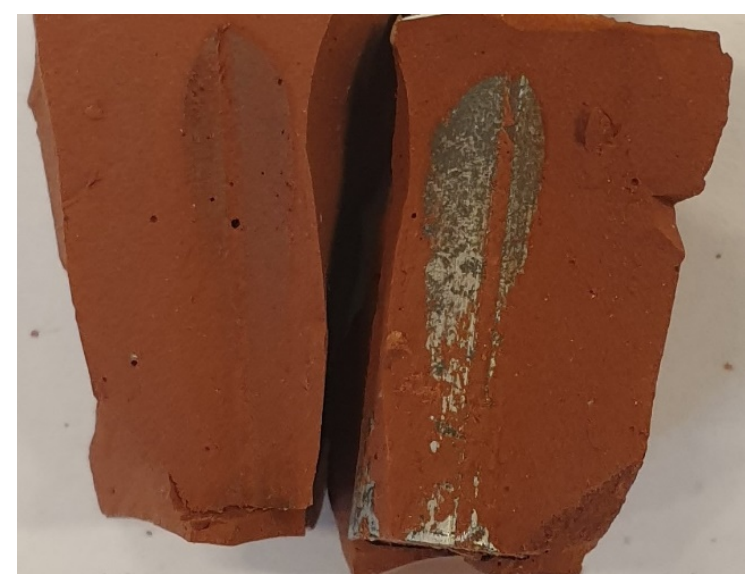

Figure 10 - Split sample of aluminium reinforced binder with 50\% AR-BR.

The hydration of parts of the aluminium reinforced paste sample was stopped by solvent exchange. The milled down sample was consequently analysed with XRD and TGA and the results are shown in Figure 11. The main hydration products were ettringite and calcium hemicarboaluminate hydrate. Portlandite appeared to be completely or almost completely consumed as no peaks for portlandite were detected with XRD or DTG. The not assigned peaks between 300 and $400^{\circ} \mathrm{C}$ in the DTG curve are most likely a combination of dehydroxylation of AFm phases and $\mathrm{Fe}$ - or Al-hydroxides from AR-BR. 
Nordic Concrete Research - Publ. No. NCR 63 - ISSUE 2 / 2020 - Article 1, pp. 1-20
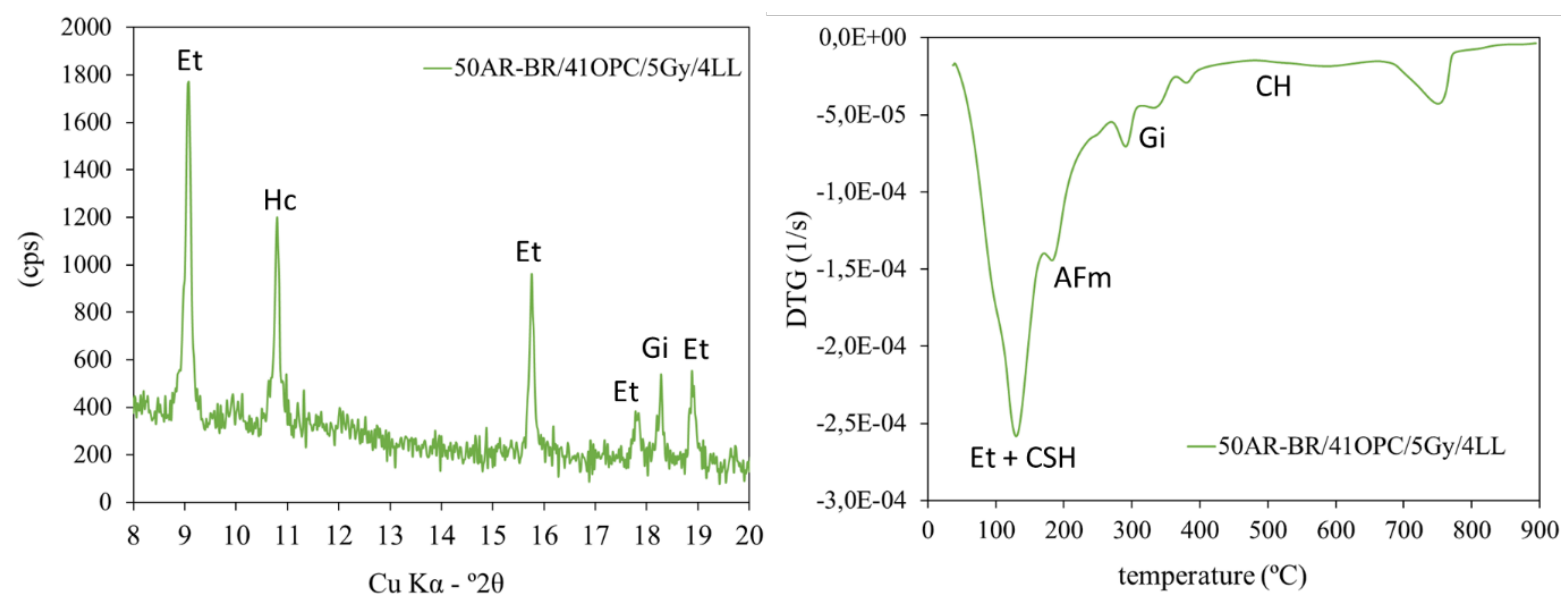

Figure $11-X R D$ (left) and DTG (right) of the aluminium reinforced paste with 50\% AR-BR. $E t=$ ettringite, $\mathrm{Hc} / \mathrm{AFm}=$ calcium hemi-carboaluminate hydrate, $\mathrm{Gi}=$ gibbsite, $\mathrm{CH}=$ portlandite

\section{6.}

\section{CONCLUSIONS}

This paper presents first results of a study on alkali reduction of bauxite residue by acetic acid treatment and the potential application of this alkali reduced bauxite residue (AR-BR) as pozzolan in cementitious binders. A process of alkali reduction is presented that can help solving waste management problems of alumina refineries while producing a reactive pozzolan and Na-acetate that can find application in the construction and infrastructure market.

- Washing of BR with acetic acid and water can result in a $\sim 90 \%$ reduction of $\mathrm{Na}_{2} \mathrm{O}$ content while only minor amounts of reactive components $\mathrm{Al}_{2} \mathrm{O}_{3}$ and $\mathrm{SiO}_{2}$ were leached out.

- Alkali reduced bauxite residue (AR-BR) showed good pozzolanic reactivity in terms of calcium hydroxide consumption and additional formation of AFm phases.

- Despite similar pozzolanic reactivity of BR and AR-BR, mortars with $20 \%$ AR-BR had considerable higher 28 -day compressive strength ( $\sim 90 \%$ of reference) than mortars with $20 \% \mathrm{BR}(\sim 75 \%$ of reference). This is a direct cause of the alkali reduction. Increasing early age strength (1 day) of mortars with AR-BR will be topic of future investigations.

- Acetic acid treatment of bauxite residue has the potential to be implemented at industrial scale at alumina refineries to solve waste management problems due to transformation of BR to a less-hazardous waste material that can be used in the construction industry. At the same time caustic soda can be regenerated to be used for the Bayer process.

- Na-acetate produced from the treatment of BR with acetic acid can potentially be used as de-icing salt for winter road maintenance.

- AR-BR is feasible to replace large amounts of cement in future binders and showed the potential to be used in durable aluminium reinforced environmentally friendly concrete construction. 
The results presented in this paper are part of the research project DARE2C; Durable Aluminium Reinforced Environmentally-friendly Concrete Construction, supported by grant no. 269767 from the Research Council of Norway. Industrial partners are Hydro, Norcem, Veidekke and Overhalla Betong.

\section{REFERENCES}

1. Yang J \& Xiao B: "Development of unsintered construction materials from red mud wastes produced in the sintering alumina process". Construction and Building Materials, Vol. 22, No. 12, 2008, pp. 2299-2307.

2. Evans K: "The History, Challenges, and New Developments in the Management and Use of Bauxite Residue". Journal of Sustainable Metallurgy, Vol. 2, No. 4, 2016, pp. 316-331.

3. Data published annually by World Aluminium. 2020, world-aluminium.org.

4. "International Aluminium Institute, Bauxite Residue Management: Best Practice". London, United Kingdom, 2015.

5. Xue S-g, Wu Y-j, Li Y-w, Kong X-f, Zhu F, William H, Li X-f \& Ye Y-z: "Industrial wastes applications for alkalinity regulation in bauxite residue: A comprehensive review". Journal of Central South University, Vol. 26, No. 2, 2019, pp. 268-288.

6. Hind A R, Bhargava S K \& Grocott S C: "The surface chemistry of Bayer process solids: a review". Colloids and Surfaces; A: Physiochemical and Engineering Aspects, No. 146, 1998, pp. 359-374.

7. Hertel T \& Pontikes Y: "Geopolymers, inorganic polymers, alkali-activated materials and hybrid binders from bauxite residue (red mud) - Putting things in perspective". Journal of Cleaner Production, Vol. 258, 2020, pp. 120610.

8. Gräfe M, Power G \& Klauber C: "Bauxite residue issues: III. Alkalinity and associated chemistry". Hydrometallurgy, Vol. 108, No. 1, 2011, pp. 60-79.

9. CEMBUREAU: "Annual Activity Report - Built in concrete, made with cement". The European Cement Association, 2018.

10. WBCSD: "Cement Industry Energy and $\mathrm{CO}_{2}$ Performace - Getting the Numbers Right (GNR)". The Cement Sustainability Initiative, 2016,.

11. Scrivener K, Vanderley J \& Gartner E: "Eco-efficient cements: Potential economically viable solutions for a low-CO2 cement-based materials industry". The United Nations Environment Programme, Paris, FRance, 2016,

12. Pontikes $\mathrm{Y}$ \& Angelopoulos G N: "Bauxite residue in cement and cementitious applications: Current status and a possible way forward". Resources, Conservation and Recycling, Vol. 73, 2013, pp. 53-63.

13. Venkatesh C, Chand M S R \& Nerella R: "A State of the Art on Red Mud as a Substitutional Cementitious Material". Annales de Chimie: Science des Materiaux, Vol. 43, No. 2, 2019, pp. 99-106.

14. Montini M, Li X, Rodrigues J A, Pileggi R G \& Scrivener K. "Cementitious Activity Evaluation of Bauxite Residue and Fly Ash combination on Portland Blended Cement ". Proceedings, TRAVAUX 48, Proceedings of the 37th International ICSOBA Conference and XXV Conference "Aluminium of Siberia", Krasnoyarsk, Russia, 2019. 
15. Danner T \& Justnes H: "Bauxite Residue as Supplementary Cementitious Material Efforts to Reduce the Amount of Soluble Sodium". Nordic Concrete Research, Vol. 62, No. 1, 2020, pp. 1-20.

16. "Opportunities for using bauxite residue in Portland cement clinker production". World Aluminium, 2016.

17. Kótai L, Sajó I, Gács I, Papp K, Bartha A \& Bánvölgyi G: "An Environmentally Friendly Method for Removing Sodium in Red Mud". Chemistry Letters - CHEM LETT, Vol. 35, 2006, pp. 1278-1279.

18. Rai S, Wasewar K, Mukhopadhyay J, Yoo C \& Uslu H: "Neutralization and Utilization of red mud for its better waste management". Arch. Environ. Sci., Vol. 6, 2012.

19. Suss A, Damaskin A, Panov A, Fennell M \& Foley S. "Specifics of Alkali Recovery from Bauxite Residue of Different Alumina Refineries". Proceedings, TRAVAUX 48, Proceedings of the 37th International ICSOBA Conference and XXV Conference "Aluminium of Siberia", Krasnoyarsk, Russia, 2019.

20. Wang S, Nguyen T, Peng H \& Huang L: "On the Mechanism of Sodic Removal from Bauxite Residue and Bauxite Desilication Products (BDP) Using Acetic Acid". JOM, Vol. 72, No. 1, 2020, pp. 309-318.

21. Snellings R, Chwast J, Cizer Ö, De Belie N, Dhandapani Y, Durdzinski P, Elsen J, Haufe J, Hooton D, Patapy C, Santhanam M, Scrivener K, Snoeck D, Steger L, Tongbo S, Vollpracht A, Winnefeld F \& Lothenbach B: "RILEM TC-238 SCM recommendation on hydration stoppage by solvent exchange for the study of hydrate assemblages". Materials and Structures, Vol. 51, No. 6, 2018, pp. 172.

22. Plusquellec G, Geiker M R, Lindgård J, Duchesne J, Fournier B \& De Weerdt K: "Determination of the $\mathrm{pH}$ and the free alkali metal content in the pore solution of concrete: Review and experimental comparison". Cement and Concrete Research, Vol. 96, 2017, pp. 13-26.

23. Kong X, Li M, Xue S, Hartley W, Chen C, Wu C, Li X \& Li Y: "Acid transformation of bauxite residue: Conversion of its alkaline characteristics". Journal of Hazardous Materials, Vol. 324, 2017, pp. 382-390.

24. Zeng H, Lyu F, Hu G, Tang H, Wang L, Sun W, Hu Y, Liu R \& Chen P. "Dealkalization of Bauxite Residue through Acid Neutralization and its Revegation Potential". Proceedings, TRAVAUX 48, Proceedings of the 37th International ICSOBA Conference and XXV Conference "Aluminium of Siberia", Krasnoyarsk, Russia., 2019.

25. Scrivener K L, Juilland P \& Monteiro P J M: "Advances in understanding hydration of Portland cement". Cement and Concrete Research, Vol. 78, 2015, pp. 38-56.

26. Berodier E \& Scrivener K: "Understanding the Filler Effect on the Nucleation and Growth of C-S-H". Journal of the American Ceramic Society, Vol. 97, No. 12, 2014, pp. 3764-3773.

27. Nguyen D D, Devlin L P, Koshy P \& Sorrell C C: "Effects of acetic acid on early hydration of Portland cement". Journal of Thermal Analysis and Calorimetry, Vol. 123, No. 1, 2016, pp. 489-499.

28. Avet F, Snellings R, Alujas Diaz A, Ben Haha M \& Scrivener K: "Development of a new rapid, relevant and reliable (R3) test method to evaluate the pozzolanic reactivity of calcined kaolinitic clays". Cement and Concrete Research, Vol. 85, 2016, pp. 1-11.

29. Jawed I \& Skalny J: "Alkalies in cement: A review: II. Effects of alkalies on hydration and performance of Portland cement". Cement and Concrete Research, Vol. 8, No. 1, 1978, pp. 37-51.

30. XRF analysis of fly ash, data from an unpublished report. 2019.

31. Thomas M, Supplementary Cementing Materials in Concrete. 2017: Taylor \& Francis Group, CRC Press. 
32. Shehata M H \& Thomas M D A: "The effect of fly ash composition on the expansion of concrete due to alkali-silica reaction". Cement and Concrete Research, Vol. 30, No. 7, 2000, pp. 1063-1072.

33. Rønning T F, Lindgård J, Karlsen J, Heimdal E, Rodum E, Hagby C, Pedersen B \& Sæter Ø: "Publikasjon nr. 21 - Bestandig betong med alkalireaktivt tilslag". Norsk Betongforening Oslo, Norway, 2017.

34. Bang S S \& Johnston D: "Environmental Effects of Sodium Acetate/Formate Deicer, Ice Shear"T". Archives of Environmental Contamination and Toxicology, Vol. 35, No. 4, 1998, pp. 580-587.

35. Al-Kheetan M J \& Rahman M M: "Integration of anhydrous sodium acetate (ASAc) into concrete pavement for protection against harmful impact of deicing salt". JOM, Vol. 71, No. 12, 2019, pp. 4899-4909.

36. Al-Kheetan M J, Ghaffar S H, Madyan O A \& Rahman M M: "Development of low absorption and high-resistant sodium acetate concrete for severe environmental conditions". Construction and Building Materials, Vol. 230, 2020, pp. 117057.

37. Justnes H: "Durable Aluminium Reinforced Environmentally-friendly Concrete Construction - DARE2C". Nordic Concrete Research, Vol. 56, No. 1, 2017, pp. 71-81.

38. Duflou J R, Tekkaya A E, Haase M, Welo T, Vanmeensel K, Kellens K, Dewulf W \& Paraskevas D: "Environmental assessment of solid state recycling routes for aluminium alloys: Can solid state processes significantly reduce the environmental impact of aluminium recycling?". CIRP Annals, Vol. 64, No. 1, 2015, pp. 37-40. 